\title{
Studies on predictive virtual models based on finite element analysis of the behaviour of geomembranes
}

\author{
Petre Vasiluta ${ }^{1}$, Nicolae Florin Cofaru, ${ }^{1, *}$, Ileana Ioana Cofaru $^{2}$ \\ ${ }^{1}$ Lucian Blaga' University of Sibiu, Industrial Engineering and Management Department, 550025, \\ Emil Cioran Street, No. 4, Sibiu, Romania \\ ${ }^{2}$ Lucian Blaga' University of Sibiu, Computer Science and Electrical Engineering Department, \\ 550025, Emil Cioran Street, No. 4, Sibiu, Romania
}

\begin{abstract}
The study shown in this paper presents the behaviour of geomembranes used at the ecological landfills. For this goal was used a method designed to elaborate the virtual models of 3D geomembrane with one ply or 2 plies disposed at $30^{\circ}, 45^{\circ}$ and $90^{\circ}$ and based on this model there were developed a number of 20 particular cases. For each situation it was realized the nonlinear analyses for all the developed cases with different vertical pressures representing different loads for the waste layer $(1 \mathrm{~m}, 2 \mathrm{~m}, 10 \mathrm{~m}, 15 \mathrm{~m}, 20 \mathrm{~m})$. The main results are obtained in graphical form and represent the Maximum tensions Von Mises and total displacements of the geomembrane.
\end{abstract}

\section{Introduction}

The apparition and evolution of the computing system allowed the automation of the conception, designing and research processes.

In this context, the FEA Concept (Finite Elements Analysis) was born from the necessity to develop some strong computing systems of resistance and data stream or fields met in engineering.

Generally, the steps of approaching a simulation based on the method of finite elements are [11]:

- Generating the tridimensional model using its own 3D modulus of definition or importing it in a CAD specialized program.

- Defining the restraints, the forces, the pressures, the sources of heat, the radiations and the laws that govern them when the analysis is ruled dynamically.

- Dividing the initial model in finite elements using different techniques in order to obtain the wanted model in the Mesh structure.

- Ruling the analysis with the aim to obtain the statistic maps of tensions, siftings and temperatures and so on.

\footnotetext{
*Corresponding author: nicolae.cofaru@ulbsibiu.ro
} 
Generally, the resulted maps regarding the static analysis and the films and the dynamic analysis express [11]:

- The stress obtains by the algorithm von Mises offering information on the charging of finite elements compared to the outside force.

- The strain of the mechanical system which reveals the lengths.

- The strain energy which offers information on the energetic consume needed to obtain the deformation status.

- The displacement which offers information on the variation of the defined nods.

In Romania the use of geosyntetic materials for construction works is regulated by MTCTNP 075/2002. The works of storage of waste and the use of geomembranes and geocomposits is regulated by Governmental Decision 162/2002 and the Technical Norms of the MAPM approved by Order 1147/2002.

In the entire world a lot of tests and studies were realized $[1,2,3,6,9,10]$ on the subject of the use of geomembranes. In a work [4] the use of protection materials installed on the geomembrane trough the experimental study was described.

In another study presented in the paper [5] the tension of encounter made in the system of the ecological deposit was analysed. The tension of encounter is due mainly to the weight of the body part elements of the ecological deposit and it varies. The phenomena of encounter between layers was also studied.

Another direction was given in a paper [7], which presented the classical lab tests analysing the puncturing effect which appears due to the sand layer currently placed on top of the geomembrane. In the tests, the liquid pressure was also taken into consideration.

In a paper [8], it was evaluated what was the mechanical answer of two polymeric geomembranes of PVC and polyethylene of 1,5 $\mathrm{mm}$ of high density, describing the phenomena in a proper mathematics model.

After analysing this worldwide published studies, it resulted the need to study the geomembrane actions when assembling and developing an ecological storage.

In this context, the current paper presents different studies using the finite element method which synthesizes the behaviour of the geomembrane submitted to different charges given by different thickness of waste pushing on it. A special attention has been offered to the plies that inevitably occur when mounting the geomembrane. These plies could have important consequences regarding the functioning and impermeability of the ecological landfill.

\section{Virtual shaping and analysis with solid element of the geomembrane}

The virtual model of the geomembrane was conceived in the Design Modeller Application, application that is a predecessor of the AnysWorkbench Application.
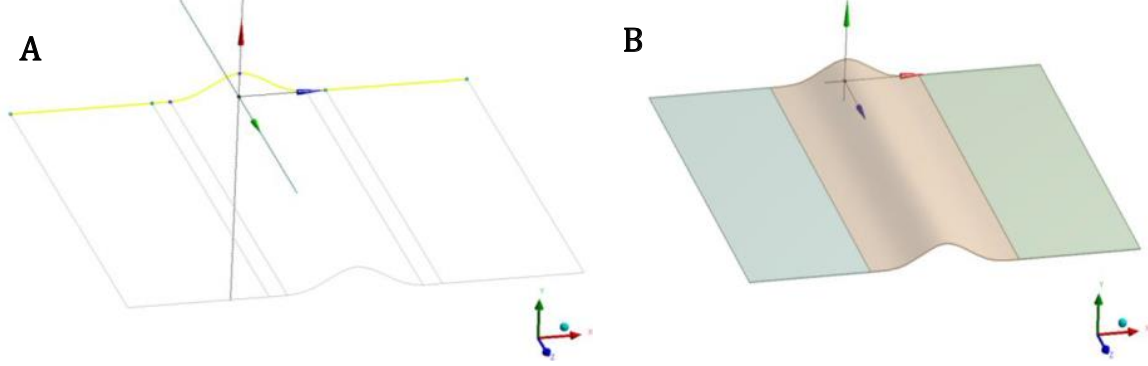

Fig. 1. A - Making the membrane surface; B - Making solid model of the membrane with a single ply. 
In order to realize the geomembrane model with one ply, it was used a sketch and then every 2 plies models used different realization methods.

In order to achieve the 3D model, the first step is to draw in the coordinates system XY the 2D model Sketch, a curve line with a height of $57 \mathrm{~mm}$ (height of the ply). The sketch (figure 1A) realized in the pre-processor Design Modeller represents the contouring shape of the geomembrane ply.
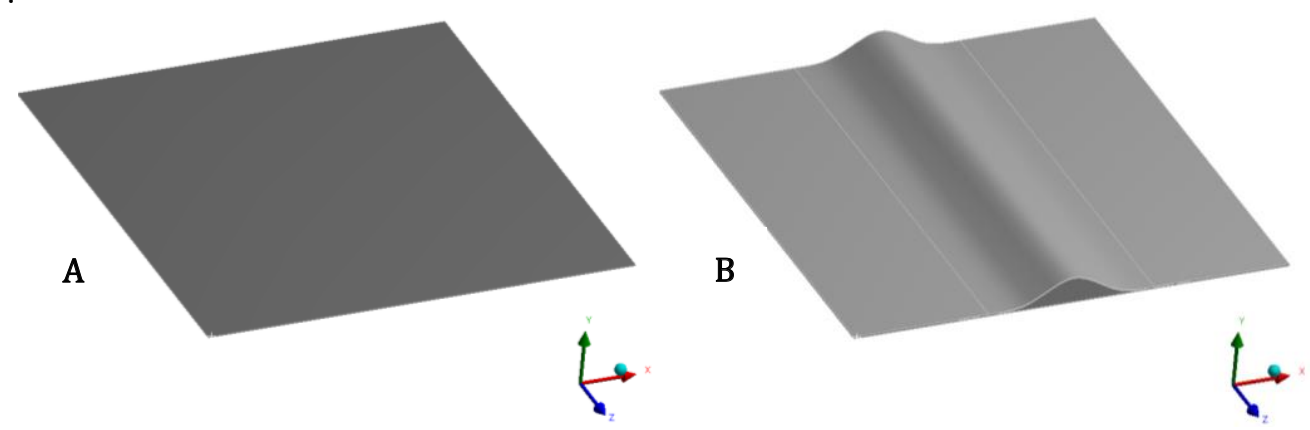

Fig. 2. A - , Ground” component; B- Virtual model geomembran1 (1ply) - , Ground”.
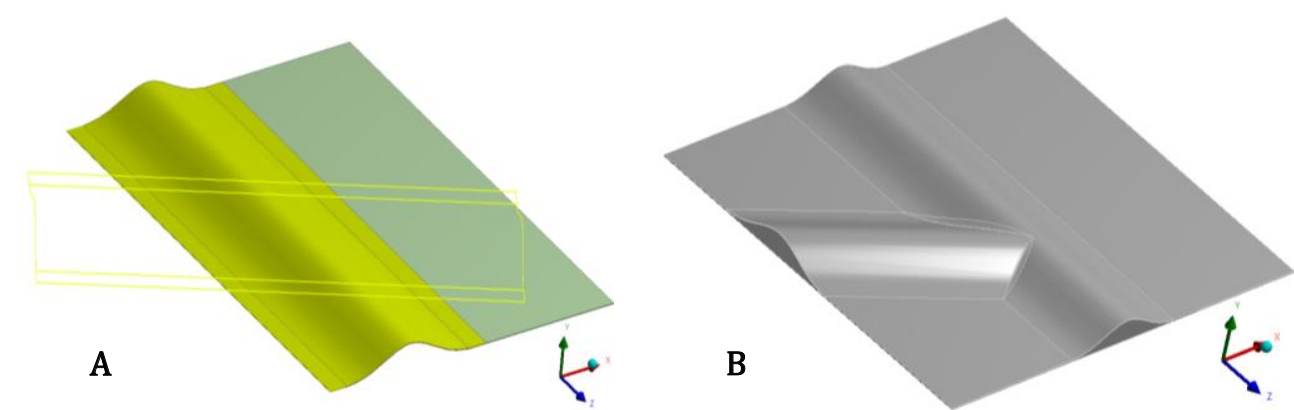

Fig. 3. A - The rotation of the ply at $-30^{\circ}$; B - The model of the geomembrane with 2 plies arranged at $30^{\circ}$ and "Ground".

The surface of the geomembrane was conceived using the commands Line from Sketch and Extrude and then defining in solid by extrusion at $2 \mathrm{~mm}$ (figure 1.B). A contact on the surface of the geomembrane was imposed in order to make the analysis in such a manner that it won't go in one Direction-Y. This component, which was a simple plate with the same exterior dimensions like geomembrane, will be called Ground (figure 2A). The 2 components can be distinguished by their colour and position in figure 2. B. It is important to mention that the surface of the model is $1 \mathrm{~m}^{2}(1 \mathrm{~m} \mathrm{x} 1 \mathrm{~m})$ and the thickness both of the geomembrane and of the Ground component is $2 \mathrm{~mm}$. In this way the surface of the ply geomembrane solid model was realised (figure 2B).

For achieving the virtual models for the geomembranes with 2 plies arranged at $30^{\circ}, 45^{\circ}$ and $90^{\circ}$, special functions were used:

- Move - for rotation of the plies at different angle.

- Substract - Boolean operation.

- Fblend - for rounded of the new components.

- Repair - for a detailed checking of the consistence of the components.

In figure 3.A the rotation of the ply at the $30^{\circ}$ is shown and in figure 3.B it is presented the model of the geomembrane with 2 plies together with "Ground" element. 
In the same way, the others 3D models of the geomembranes with 2 plies disposed at $30^{\circ}, 45^{\circ}$ and $90^{\circ}$ were achieved. In order to achieve a nonlinear static analysis with shell elements these 3D models used were suitable.

\section{Nonlinear analysis of the geomembrane with 2 plies}

In the following, the elaboration of the nonlinear static analysis for the geometric model of the 2 plies $30^{\circ}$ geomembrane with shell elements will be presented. The 2 components were placed in a global XYZ system in order to correctly place the degrees of freedom of the 2 components.

The discretization of the geometric model in nods and elements was realized with 186 Solid hexahedric elements and 187 Solid tetraedic elements, both solid elements with middle nods. The middle nods are necessary in order to better approximate the results.

The Sweep method was used in order to discretize the elements for the Ground component, automatically controlling the formation direction of the source elements to the interest area.

For the encounter zones of ply surfaces, due to the fact that they are hard to discretize, advanced discretization methods were used, like HexDominant and PatchConforming, those being methods used to encounter the hexaedric and tetraedic elements. In order to obtain an efficient discretization the $10 \mathrm{~mm}$ and $20 \mathrm{~mm}$ dimensions were used.

Following the solving of the nods and elements network, 42.731 nods and 15.125 elements resulted (figure 4).

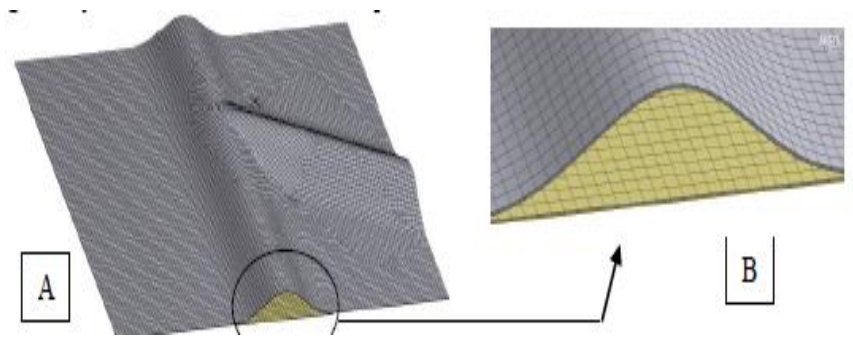

Fig. 4. A - Network modes and items obtained for model membrane 2 folds arranged at $30^{\circ}-$ "Ground"; B - Picture fold local area.

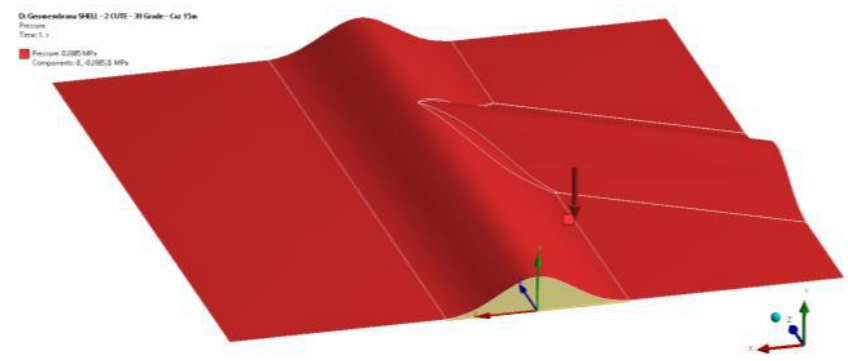

Fig. 5. Applying pressure evenly distributed on the upper surface of the membrane 2 folds arranged at $30^{\circ}$.

In order to realize this analysis, the limit conditions used were:

- Virtual time for run of the analysis was set at $1 \mathrm{sec}$.

- The solver was set as one being the iterative type using PCG method (,Preconditioned Conjugate Gradient") level 2.

- Constraining the "ground component” using the commands „Fixed Support” on the bases surfaces, DOF $=0$ (degree of freedom).

-Applying a Normal uniform distributed pressure on the superior surfaces of the geomembrane with a value dependent of the height of the waste $(1 \mathrm{~m}, 2 \mathrm{~m}, 10 \mathrm{~m}, 15 \mathrm{~m}, 20 \mathrm{~m})$ (figure 5). 
- Constraining the geomembrane on the exterior lines (parallel with the ply) using also the command Fixed Support.

- Constraining the lateral surfaces of the geomembrane with the support „Frictionless Support", blocking in this way the movement on the perpendicular direction.

The characteristics of the isotropic material used for the geomembrane are shown in Figure 6. The image is the caption from simulation module „Data Engineering”.

\begin{tabular}{|c|c|c|c|c|}
\hline & A & B & \multicolumn{2}{|c|}{ c } \\
\hline 1 & Property & Value & \multicolumn{2}{|c|}{ Unit } \\
\hline 2 & 7 Density & 1020 & $\mathrm{~kg} \mathrm{~m} \mathrm{~m}^{\wedge}-3$ & $=$ \\
\hline 3 & 曰绉 Isotropic Secant Coefficient of Thermal Expansion & & & \\
\hline 4 & Coefficient of Thermal Expansion & 0.00176 & $C^{\wedge}-1$ & $\nabla$ \\
\hline 5 & 7 Reference Temperature & 22 & C & $\nabla$ \\
\hline 6 & 曰 7 Isotropic Elasticity & & & \\
\hline 7 & Derive from & Young's Modulus and Poisson's Ratio & & \\
\hline 8 & Young's Modulus & 2000 & $\mathrm{MPa}$ & $=$ \\
\hline 9 & Poisson's Ratio & 0.394 & & \\
\hline 10 & Bulk Modulus & $3.1447 E+09$ & $\mathrm{~Pa}$ & \\
\hline 11 & Shear Modulus & $7.1736 \mathrm{E}+08$ & $\mathrm{~Pa}$ & \\
\hline 12 & 7 Tensile Yield Strength & 63 & $\mathrm{MPa}$ & $\nabla$ \\
\hline 13 & 7 Compressive Yield Strength & 0 & $\mathrm{MPa}$ & $\nabla$ \\
\hline 14 & 7 Tensile Ultimate Strength & 33 & $\mathrm{MPa}$ & $\nabla$ \\
\hline 15 & 7 Compressive Ultimate Strength & 0 & $\mathrm{MPa}$ & $\nabla$ \\
\hline 16 & 7 Isotropic Thermal Conductivity & 0.2256 & $W m^{\wedge}-1 C^{\wedge}-1$ & $\nabla$ \\
\hline 17 & 7 Specific Heat & 1386 & $\mathrm{Jg} \wedge-1 \mathrm{C}^{\wedge}-1$ & \pm \\
\hline
\end{tabular}

Fig. 6. The characteristics of the isotropic material used for the geomembrane.

For the results set the following values were extracted: Total displacement, Equivalent total strain, Maximum equivalent Von Mises Stress, Maximum principal stress, Minimum principal stress.

In figure 7 it is shown the map of the Maximum equivalent Von Mises Stress.

The area of interest and importance is the maximum stress Von Mises and total displacement of the membrane. Due to the pressure imposed by $0.0192 \mathrm{MPa}$, total displacement is $25.38 \mathrm{~mm}$ and the maximum value calculated for maximum tension membrane is equivalent to $29.82 \mathrm{MPa}$.

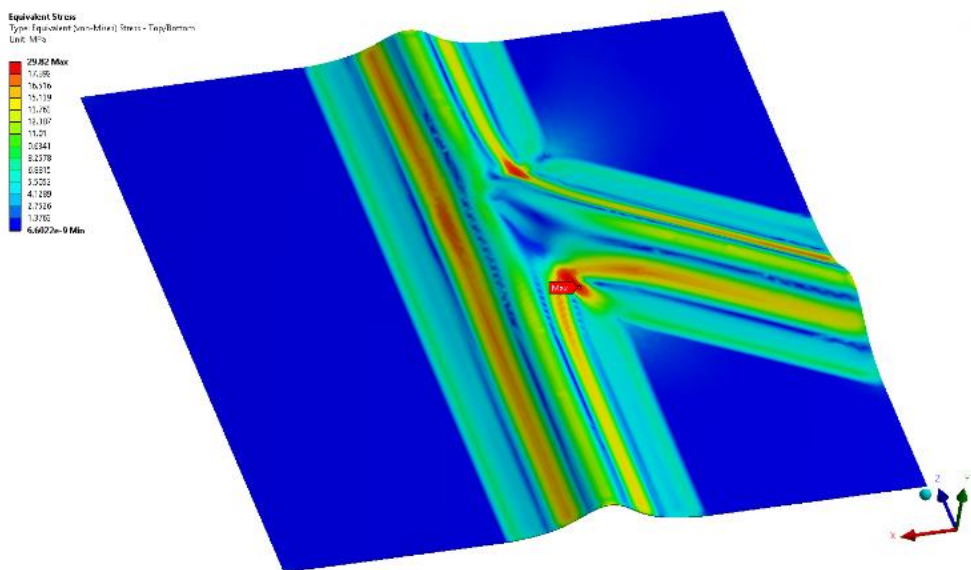

Fig. 7. Maximum equivalent Von Mises Stress. 
These values were obtained at the analysis of the $30^{\circ}, 2$ plies geomembrane model with Shell elements for the application of the tension given by the waste layer with the $1 \mathrm{~m}$ length. The $0.192 \mathrm{MPa}$ tension is applied on a $1 \mathrm{~m}^{2}$ surface of the geomembrane. The values obtained for the 5 analyses with the respective tensions and waste layers of $1 \mathrm{~m}, 5 \mathrm{~m}, 10 \mathrm{~m}$, $15 \mathrm{~m}$, and $20 \mathrm{~m}$ for the total deformation, Equivalent Total Strain and the Equivalent Total Strain can be found in Table 1.

Table 1. Values obtained for the 5 cases developed membrane with 2 plies arranged at $30^{\circ}$ analysed with shell element.

\begin{tabular}{|c|c|c|c|c|}
\hline $\begin{array}{c}\text { H } \\
{[\mathbf{m}]}\end{array}$ & $\begin{array}{c}\text { PESD } \\
{[\mathbf{M P a}]}\end{array}$ & $\begin{array}{c}\text { DT } \\
{[\mathbf{m m}]}\end{array}$ & $\begin{array}{c}\text { DET } \\
{[\mathbf{m m} / \mathbf{m m}]}\end{array}$ & $\begin{array}{c}\text { TME } \\
{[\mathbf{M P a}]}\end{array}$ \\
\hline 1 & 0,0192 & 25,38 & 0,0375 & 29,82 \\
\hline 5 & 0,0961 & 35,99 & 0,0599 & 39,73 \\
\hline 10 & 0,1923 & 41,13 & 0,9973 & 57,01 \\
\hline 15 & 0,2885 & 45,78 & 0,1279 & 60,14 \\
\hline 20 & 0,3846 & 47,69 & 0,1413 & 66,14 \\
\hline
\end{tabular} \begin{tabular}{l} 
H - height layer of waste; \\
ESDP - pressure from the layer of waste; \\
DT - total displacement; \\
DET - total equivalent strain; \\
TME - the maximum stress equivalent von Mises \\
\hline
\end{tabular}

Table 2. Values obtained for the 20 cases developed membrane analysed with shell elements.

\begin{tabular}{|c|c|c|c|c|c|c|c|}
\hline \multirow{2}{*}{$\begin{array}{c}\mathbf{H} \\
{[m]}\end{array}$} & \multirow{2}{*}{$\begin{array}{l}\text { PESD } \\
{[M P a]}\end{array}$} & \multicolumn{3}{|c|}{$\begin{array}{c}\text { Geomembrane } 1 \text { PLY - } \\
\text { Shell }\end{array}$} & \multicolumn{3}{|c|}{$\begin{array}{c}\text { Geomembrane } 2 \text { PLIES - 30 } \\
\text { - Shell }\end{array}$} \\
\hline & & $\begin{array}{c}\mathrm{DT} \\
{[\mathrm{mm}]}\end{array}$ & $\begin{array}{c}\mathrm{DET} \\
{[\mathrm{mm} / \mathrm{mm}]}\end{array}$ & $\begin{array}{c}\text { TME } \\
{[M P a]}\end{array}$ & $\begin{array}{c}\mathrm{DT} \\
{[\mathrm{mm}]}\end{array}$ & $\begin{array}{c}\mathrm{DET} \\
{[\mathrm{mm} / \mathrm{mm} /}\end{array}$ & $\begin{array}{l}\text { TME } \\
{[M P a]}\end{array}$ \\
\hline 1 & 0,0192 & 29,44 & 0,0249 & 23,68 & 25,38 & 0,0375 & 29,82 \\
\hline 5 & 0,0961 & 41,78 & 0,0450 & 32,05 & 35,99 & 0,0599 & 39,73 \\
\hline 10 & 0,1923 & 45,64 & 0,0672 & 50,54 & 41,13 & 0,9973 & 57,01 \\
\hline 15 & 0,2885 & 47,35 & 0,0775 & 59,23 & 45,78 & 0,1279 & 60,14 \\
\hline 20 & 0,3846 & 49,72 & 0,0963 & 64,18 & 47,69 & 0,1413 & 66,14 \\
\hline \multicolumn{2}{|c|}{-} & \multicolumn{3}{|c|}{$\begin{array}{c}\text { Geomembrane } 2 \text { PLIES - } \\
45^{\circ} \text { - Shell }\end{array}$} & \multicolumn{3}{|c|}{$\begin{array}{c}\text { Geomembrane } 2 \text { PLIES - } \\
90^{\circ} \text { - Shell }\end{array}$} \\
\hline 1 & 0,0192 & 27,14 & 0,0379 & 31,11 & 32,81 & 0,0384 & 32,10 \\
\hline 5 & 0,0961 & 37,03 & 0,0507 & 43,19 & 38,17 & 0,0406 & 45,12 \\
\hline 10 & 0,1923 & 42,15 & 0,0671 & 59,02 & 41,71 & 0,0852 & 59,43 \\
\hline 15 & 0,2885 & 46,22 & 0,0993 & 63,79 & 45,61 & 0,0929 & 64,11 \\
\hline 20 & 0,3846 & 51,31 & 0,1129 & 68,23 & 49,17 & 0,1213 & 68,63 \\
\hline
\end{tabular}

Using the same approach, the virtual models of 3D geomembrane with one ply or 2 plies disposed at $30^{\circ}, 45^{\circ}$ and $90^{\circ}$ were achieved ( 20 particular cases).

The obtained values for different tensions from the waste layers are presented in table 2 . The abbreviations used in Table 2 are the same as those used in Table 1.

It can be observed that by applying a pressure of $0.0192 \mathrm{MPa}(1$ meter height layer waste), the maximum total displacement is $32.81 \mathrm{~mm}$ and the maximum stress equivalent von Mises is $32.10 \mathrm{MPa}$. This values were obtained for the geomembrane with 2 plies disposed at $90^{\circ}$. By applying a maximum pressure of $0.0348 \mathrm{MPa}(20$ meter height layer waste), the maximum total displacement is $51.31 \mathrm{~mm}$ obtained for the geomembrane with 2 
plies disposed at $45^{\circ}$, whereas the maximum stress equivalent von Mises was reached for the geomembrane with 2 plies disposed at $90^{\circ}$.

\section{Conclusions}

The main goal of this paper is to analyse the geomembrane behaviour, using the finite element method, in different situations. The main original contributions are the following. It was realised a numerical simulation of the geomembrane by the 4 developed models each and every one with 5 different loading cases. It was realized a static nonlinear analysis for all the developed cases with different vertical tensions representing different heights for the waste layer $(1 \mathrm{~m}, 2 \mathrm{~m}, 10 \mathrm{~m}, 15 \mathrm{~m}$, and $20 \mathrm{~m})$. In the paper are presented the analysis conditions for the simulations, the limit conditions and the material characteristics. There were extracted images for the maximum tensions Von Mises and for the total deformations of the geomembrane. By undergoing a comparative analysis with these cases, it resulted that:

- All evaluated parameters in all cases increase with the height of waste layer.

- For the maximum value of the waste layer $(20 \mathrm{~m})$, the total displacement is minimum for 2 plies disposed at $30^{\circ}$ and maximum for 2 plies disposed at $45^{\circ}$, the total equivalent strain is minimum for 1 ply and maximum for 2 plies disposed at $30^{\circ}$ and the maximum stress equivalent von Mises is minimum for 1 ply and maximum for 2 plies disposed at $90^{\circ}$

Because the appearance of the plies is inevitable at the mounting of the geomembrane it would be better to manage the disposition of these plies. According with this study it's important to avoid the situations when the values of the studied parameters are maximal because in these positions of the plies it is possible to damage the geomembrane with bad consequences on the good functioning and on the non-permeability of the ecological landfill.

We consider that the study is very important in order to achieve a good and correct mounting of the geomembrane.

\section{References}

1. D. Barbulescu, Research on membrane protection dams against infiltration of local materials, $\mathrm{PhD}$ Thesis, Technical University of Civil Engineering, Faculty of Hydrology, Bucharest, (2011).

2. S. J. E. Dickinson, Physical Response of Composite Geomembrane/Geosinthetic Clay Liners under Simulated Landfill Conditions, PhD Thesis, Queen's University, Kingston, Ontario, Canada (2008).

3. J. P. Giroud, K. Badu-Tweneboah, K.L. Soderman, 6, 1019-1048 (1995).

4. P.J. Fox, J.D. Ross, J.M. Sura, R.S. Thiel, Geosyntetics International 5 (18), 272-279 (2011).

5. Y.L. Kwang, G.C. Chin, J.H Taik, H.Y. Seong, The Stress-Strain Behaviour of Geotextiles under Puncture Loads in a Liner System, Proceedings of The Twelfth International Offshore and Polar Engineering Conference, Kitakyushu, Japan (2002).

6. S.M Merry, J.D Bray, Geosynthetics International 3 (4), 517-536 (1996).

7. W. Haimin, S. Yiming, D. Linjun, T. Zhaoming, Mechanical Behaviour of Interface between Composite Geomembrane and Permeable Cushion Material, Hindawi Publishing Corporation, (2014).

8. A.Z. Katarzyna, D. Neil, F. Gary, D. Russel, V. Jones, B.Zhang, Geotextiles and Geomembranes, 224-235, (2014). 
9. K.V.N. Raviteja, B. Munwar, S. Basha, Variability Associated with interface friction between geomembrane and soil. $50^{\text {th }}$ Indian Geotechnical Conference, Pune, India, (2015).

10. S. Seeger, H. Böhm, G. Söhring, W. Müller, Long term testing of geomembranes and geotextiles under shear stress, Federal Institute of Materials Research and Testing (BAM), Berlin, Germany, (2015)

11. V. Oleksik, A. Pascu, Proiectarea optimală a maşinilor şi utilajelor, Editura Universităţii „Lucian Blaga” din Sibiu, ISBN 978-973-739-431-6, (2007) 